\title{
Commentary: Achieving geometrical symmetry in bicuspid aortic valve repair: Expert hands make the difference
}

\author{
Luca Botta, MD, PhD, Giacomo Murana, MD, PhD, Alessandro Leone, MD, PhD, \\ Luca Di Marco, MD, PhD, and Davide Pacini, MD, PhD
}

\footnotetext{
From the Cardiac Surgery Unit, Cardio-Thoraco-Vascular Department, S. Orsola Hospital, University of Bologna, Bologna, Italy.

Disclosures: Authors have nothing to disclose with regard to commercial support.

Received for publication June 26, 2019; accepted for publication June 28, 2019; available ahead of print Aug 13, 2019.

Address for reprints: Davide Pacini, MD, PhD, Cardio-Thoraco-Vascular Department, Cardiac Surgery Unit, S. Orsola Hospital, University of Bologna, Via Massarenti 9, 40138, Bologna, Italy (E-mail: davide.pacini@ aosp. bo.it).

J Thorac Cardiovasc Surg 2020;159:e37-8

$0022-5223 / \$ 36.00$

Copyright (C) 2019 by The American Association for Thoracic Surgery

https://doi.org/10.1016/j.jtcvs.2019.06.079
}

Symmetry is obtained when things are the same around an axis. Finding symmetries is one key for understanding fundamental physics. Some physicists have suggested that the ultimate law in the universe is not symmetric but that the symmetry appears as an illusion at lower levels of perception. ${ }^{1,2}$ During the 13th century, the mathematician Fibonacci described his famous sequence, in which the ratio of every consecutive number approximates the value of 1.618. From this sequence, it is possible to generate a spiral (Fibonacci spiral) that is worldwide present: from sunflowers and shells to geometric figures (regular hexagon and pentagon). ${ }^{3}$ Symmetry is a central concept in aesthetics and plays an essential role in art, architecture, design, literature, and music. As cardiac surgeons, we are fascinated by the perfect geometry of the aortic valve that approximates a predetermined ratio of 1.618 (golden ratio), and the Fibonacci spiral would fit into the valve, representing an interesting way to describe its attractive symmetry. ${ }^{3}$ Perfect symmetry can be lost in cases of (pathological) bicuspid aortic valves (BAVs). The surgical technique described by Urbanski ${ }^{4}$ leads to an achievement of a $180^{\circ}$ coaptation line between the cusps of a BAV and to an achievement of cusp symmetry with a coaptation line that runs through the middle of the root. This technique is applied in patients with regurgitant BAV, nearly normal aortic roots $(\leq 4.5 \mathrm{~cm})$ and with normal aortic wall quality. A patch enlargement of the unfused cusp sinus and a narrowing of the corresponding width of aortic wall on the opposite side are associated with cusp repair. This procedure seems to offer an improved orifice area with a symmetrical cusp movement, lower transvalvular gradient, and probably better long-term durability. Although surgical manipulation of the aortic root can be simple and nonrisky in the hands of experienced surgeons, it is evident that a nonmandatory patch enlargement and a sinus narrowing

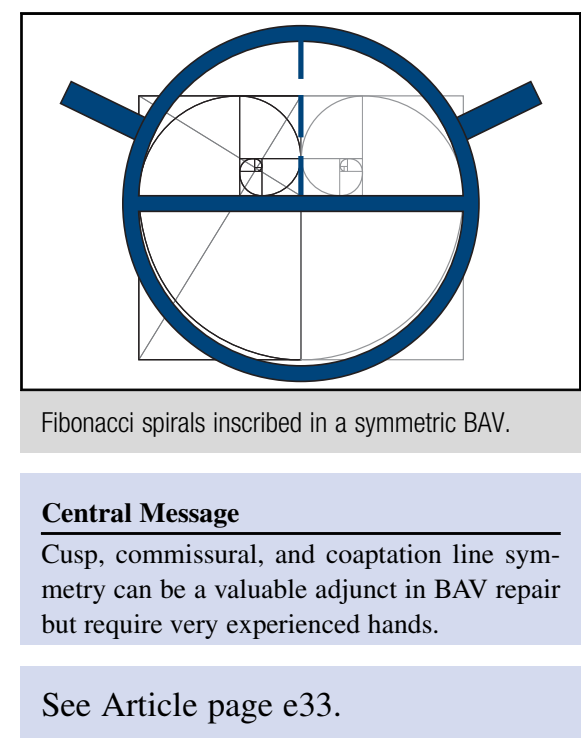

of the root can lead to undesirable complications and be more dangerous than useful in patients with uncertain (histologically) wall quality, despite a normal size. This search for symmetry does not rely on standardized intraoperative measurements but is visually assessed by an expert's eye. This makes the procedure difficult to reproduce. As for every new technique, time will tell us if it is worthwhile because mid- and long-term results are still not available. The introduction of a new surgical technique enriches the surgical community and is always welcome, but we should keep in mind that achieving geometrical symmetry in BAV requires expert hands, particularly when a root remodeling or reimplantation is not necessary. The reduced number of isolated BAV repairs published in the literature and its origin by well-known hub centers ${ }^{4,5}$ let us understand the need for a peculiar expertise. Standardization and reproducibility of complex (at least for many surgeons) procedures will require a long learning curve. The real world knows how true is the aphorism commonly attributed to Voltaire: The best is the enemy of the good. Trying to make something perfect can actually prevent us from making it just good. In nature, symmetry implies transformation and transformation implies simplicity. We impose the symmetries on the world to understand it, but we should remember that nature herself is not perfectly symmetric. 


\section{References}

1. Wilczek F. In search of symmetry lost. Nature. 2005;433:239-47.

2. Zee A. Symmetry and the search for beauty in modern physics. In: New Literary History. Papers from the Commonwealth Center for Literary and Cultural Change. Baltimore, MD: The Johns Hopkins University Press; 1992;23:815-38.

3. Moscarelli M, De Paulis R. The golden perfection of the aortic valve. Int J Cardiol. 2016;205:165-6.
4. Urbanski PP. Repair of bicuspid aortic valve: Simple and effective achieve ment of symmetric valve orientation. J Thorac Cardiovasc Surg. 2020;159: e33-6.

5. de Kerchove L, Mastrobuoni S, Froede L, Tamer S, Boodhwani M, van Dyck M, et al. Variability of repairable bicuspid aortic valve phenotypes: towards an anatomical and repair-oriented classification. Eur J Cardiothorac Surg. Feb 20, 2019 [Epub ahead of print]. 